\title{
Photochemistry of clobetasol propionate, a steroidal anti- inflammatory drug
}

\author{
Jawaid Iqbal*, Anamika Gupta, and Adil Husain \\ Organic Chemistry Section, Department of Chemistry, Aligarh Muslim University, \\ Aligarh 202002 (U.P) India \\ E-mail: jawaid.iqbal0@lycos.com
}

\begin{abstract}
The photochemistry of the anti-inflammatory drug clobetasol propionate $\mathbf{1}$ was studied in aerobic as well as in anaerobic condition with different irradiation wavelengths (254 nm and $310 \mathrm{~nm}$ ) in acetonitrile and 2-propanol. Photoproducts obtained were isolated and characterized on the basis of IR, ${ }^{1} \mathrm{H}$ NMR, ${ }^{13} \mathrm{C}$ NMR spectroscopy and elemental analysis. The products were: 21-chloro-9fluoro-11-hydroxy-16-methyl-17(1-oxopropoxy)-1,5-cyclopregn-3-ene-2,20-dione 2 (254 nm), 21-chloro-9-fluoro-11-hydroxy-16-methyl-17(1-oxopropoxy)-18,20-cyclopregn-1,4-diene-3-one 3 (310 nm/2-propanol, argon), 9-fluoro-17-hydroperoxy-16-methyl-17(1-oxopropoxy)androsta1,4-diene-3-one 4 (310 nm/O $/ 2$-propanol). Cyclohexadienone moiety in ring $\mathrm{A}$ and keto group at $\mathrm{C}_{17}$ were found to be deeply modified by U.V light and therefore loss of biological activity during storage and in vivo cannot be ruled out.
\end{abstract}

Keywords: Photochemistry, clobetasol propionate, anti-inflammatory drug

\section{Introduction}

Polyfunctional molecules in which different photochemically reactive chromophores are connected by a rigid hydrocarbon framework are a subject of fascinating photochemistry. ${ }^{1-3}$ The intramolecular energy transfer (both singlet-singlet and triplet-triplet) may occur from an 'antenna' group to other chromophore leading to chemistry different from that observed by direct excitation of that chromophore. ${ }^{4-7}$ In the photochemistry of such multichromophoric molecules the evaluation of interaction between the chromophores, the mode and extent of local reaction at any chromophore after electronic excitation and possible role of energy transfer are highly significant for mechanistic evaluation.

Morrison established through a series of elegant papers ${ }^{4-7}$ that intramolecular energy transfer (both singlet-singlet and triplet-triplet) occurred from the phenyl 'antenna' to $\mathrm{C}_{17}$ keto group by the way of through-bond mechanism. This has led to a different photochemistry observed by the direct excitation of ketone chromophore. Albini et al. ${ }^{8,}{ }^{9}$ have demonstrated non- 
communicating reaction paths in pregna-1, 4-diene-3, 20-dione. Since many steroidal drugs are commonly used and several reports on their phototoxic effects have been reported, ${ }^{10-13}$ it was of interest to extend this subject of study of the competition between chemical reactions of the separated excited moieties incorporated in the rigid skeleton of the steroids. It was expected that such photochemical mechanisms might have relevance for the mechanism of phototoxicity.

Glucocorticosteroids are natural hormones with a steroidal structure derived from $5 \alpha-$ pregnane. These steroidal hormones with powerful anti-inflammatory effects are secreted by the cortex of adrenal gland. Semisynthetic derivatives of these hormones are widely used as drugs to treat inflammatory illnesses, including arthritis, asthma and many of them are effective by topical use in dermatomes and other dermatological diseases.

Clobetasol propionate (1) is a dihalogenated highly potent glucocorticoid. It is an analog of prednisolone. It is used only topically on the skin and its effects are limited to the local antiinflammatory activity. Clobetasol is indicated for the treatment of psoriasis, ${ }^{14}$ dry hyperkeratotic dermatoses, initial control of all forms of hyperacute eczema, chronic hyperkeratotic eczema, contact dermatitis, atopic dermatitis, lichen planus associated with severe pruritis, discoid lumps erythema and granulomatous disorders. ${ }^{15,16}$

Clobetasol propionate has a characteristics UV absorption at $\lambda_{\max }(\mathrm{MeOH}) 237 \mathrm{~nm}$ $(\varepsilon=15000)$. It is very interesting from photochemical point of view because it bears two spatially separated chromophores i.e. cyclohexadienone moiety in ring $\mathrm{A}$ and carbonyl group at $\mathrm{C}_{20}$. A number of photochemical studies have been carried out on these steroidal ketones, both in

solution and in solid state. ${ }^{17-23}$ The photochemistry of cross-conjugated cyclohexadienone has been intensively studied because of their facile and fascinatingly complex photochemical reactions. Williams et al. ${ }^{24}$ carried out photolysis of prednisolone at $254 \mathrm{~nm}$ and observed that the only photoprocess occurring in dioxane solution was the "lumiketone" rearrangement of the cyclohexadienone moiety. With this interest herein we have investigated the photochemistry of clobetasol under different combinations of solvents and irradiation wavelengths.

\section{Results and Discussion}

When clobetasol was irradiated at $254 \mathrm{~nm}$ in argon flushed acetonitrile or in oxygen saturated solution it gave compound $\mathbf{2}$ as product. The photoreactions of $\mathbf{1}$ in 2-propanol at $254 \mathrm{~nm}$ followed a similar course of reaction under aerobic as well as anaerobic conditions. Irradiation at $310 \mathrm{~nm}$ either in argon saturated acetonitrile or 2-propanol gave product 2 along with a new compound 3. At the same irradiation wavelength $(310 \mathrm{~nm})$ saturation of the solution with oxygen affected the product distribution: in 2-propanol $\mathbf{3}$ was not formed and hydroperoxide $\mathbf{4}$ was obtained as main product along with 2 . In acetonitrile a complex mixture of products was obtained (Scheme 1). The comparative yields of the photoproducts (2, 3 and 4) under different reaction conditions are given in Table 1. 
Table 1. Yields of the reaction products, in photochemical reaction of (1) under different reaction conditions

\begin{tabular}{|l|l|l|l|}
\hline Solvent conditions & Wavelengths & Photoproduct(s) & $\begin{array}{l}\text { Yields of the products } \\
(\%)\end{array}$ \\
\hline $\mathrm{CH}_{3} \mathrm{CN} /$ Argon & $254 \mathrm{~nm}$ & $\mathbf{2}$ & $47 \%$ \\
\hline $\mathrm{CH}_{3} \mathrm{CN} /$ Argon & $310 \mathrm{~nm}$ & $\mathbf{3}+\mathbf{2}$ & $\begin{array}{l}\mathbf{3}(39 \%) ; 2 \text { (trace on } \\
\text { TLC) }\end{array}$ \\
\hline $\mathrm{CH}_{3} \mathrm{CN} /$ Oxygen & $254 \mathrm{~nm}$ & $\mathbf{2}$ & $48 \%$ \\
\hline $\mathrm{CH}_{3} \mathrm{CN} /$ Oxygen & $310 \mathrm{~nm}$ & $\begin{array}{l}\text { A complex mixture } \\
\text { of products }\end{array}$ & \\
\hline 2-Propanol/Argon & $254 \mathrm{~nm}$ & $\mathbf{2}$ & $52 \%$ \\
\hline 2-Propanol/Argon & $310 \mathrm{~nm}$ & $\mathbf{3}+\mathbf{2}$ & $\mathbf{3}(37 \%) ; 2(15 \%)$ \\
\hline 2-Propanol/Oxygen & 254 & $\mathbf{2}$ & $56 \%$ \\
\hline 2-Propanol/Oxygen & 310 & $\mathbf{4 + 2}$ & $\mathbf{4}(43 \%) ; 2(18 \%)$ \\
\hline
\end{tabular}

*Yields of the products after isolation and purification.

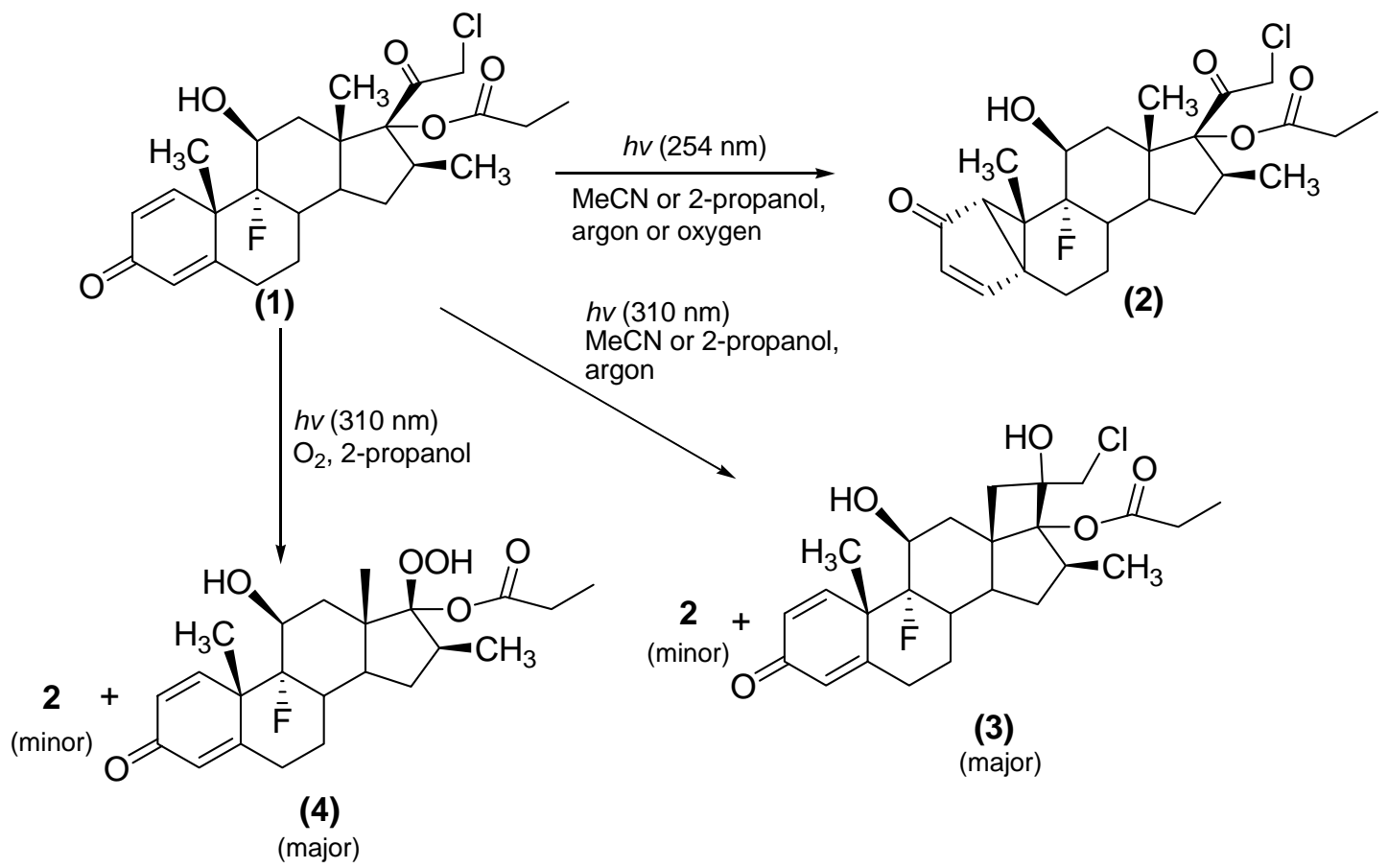

\section{Scheme 1}

These results can be rationalized on the basis of a different mechanism of the photochemical reaction of the two-separated chromophores present in this drug. At $254 \mathrm{~nm}$, cross-conjugated ketone absorbs predominantly or exclusively, which causes the well-known lumiketone rearrangement ${ }^{25,26}$ of this chromophore and leads to the formation of compound 2 
(Scheme 2). The rearrangement leading to $\mathbf{2}$ is a concerted process and therefore, not affected by the solvent medium.

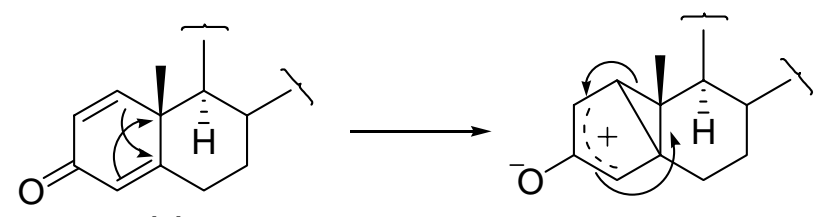

(1)
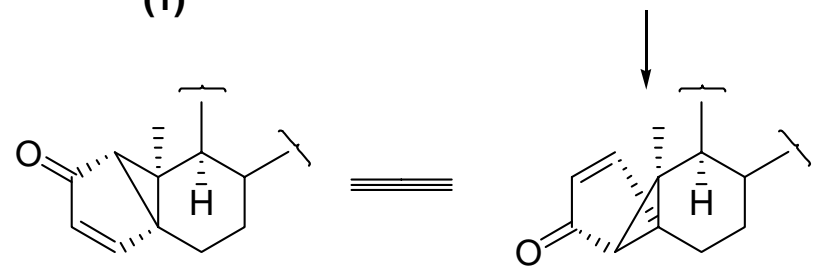

(2)

\section{Scheme 2}

On the contrary, at $310 \mathrm{~nm}$, where isolated ketone at $\mathrm{C}_{20}$ absorbs a large fraction of light, compound 3 was obtained as the product, which arises via hydrogen atom abstraction from the close lying 18-methyl group followed by cyclization (Scheme 3). In oxygen saturated solution trapping of alkyl radicals by oxygen is quite efficient to yield peroxy radicals. This peroxy radical abstracts hydrogen from hydrogen donating solvent (2-propanol) and gives the isolated hydroperoxy derivative 4 (Scheme 4).

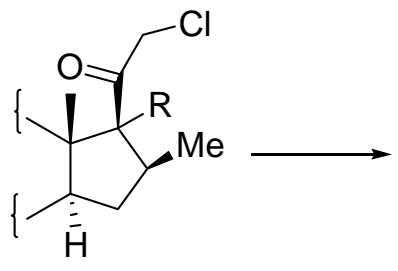

(1)

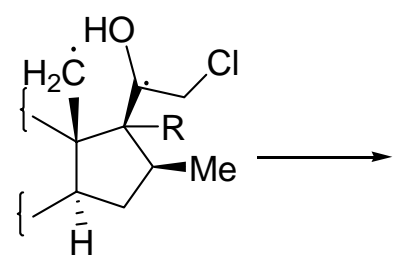

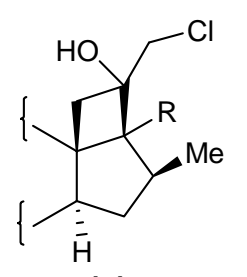

(3)

\section{Scheme 3}

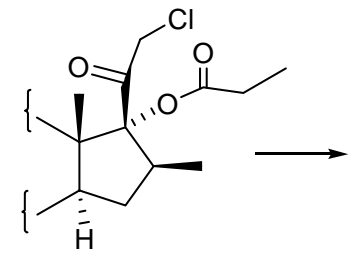

(1)<smiles>CC(=O)O[C@H]1[C@@H](C)C[C@H](I)[C@]1(C)I</smiles>

(1a)<smiles>CCCCC1CC(I)C(I)(I)C1(OC(=O)OCC)C(C)C</smiles>

(4)

\section{Scheme 4}


All the products obtained were characterized on the basis of the following spectral evidence. The IR spectrum of 2 showed absorption bands at 1350, 1161, 1030 (cyclopropyl), $1570(\mathrm{C}=\mathrm{C}), 1675(\mathrm{C}=\mathrm{O})$. In the NMR spectrum of 2 , signals due to the rings $\mathrm{B}, \mathrm{C}$ and $\mathrm{D}$ were found to be unaffected while signals due to ring A were strongly modified since only two of the olefinic $\mathrm{CH}$ were conserved and third was substituted by a $\mathrm{sp}^{3}$ carbon. Two doublets centered at $\delta 6.66$ and 5.68 with $\mathrm{J}=6.2 \mathrm{~Hz}$ in the ${ }^{1} \mathrm{H}-\mathrm{NMR}$ spectrum and the IR band values indicated the presence of an $\alpha, \beta$-unsaturated ketone in ring A. A proton singlet at $\delta 1.06$ and ${ }^{13} \mathrm{C}$-NMR signals at 40.4, 25.2 and 27.1 indicated a cyclopropyl carbonyl system in ring A. Proof of the stereochemistry came from a comparison of its circular dichroism spectra with those of other lumiketones that showed positive and negative cotton effects of similar magnitude and position to those reported in litrature ${ }^{27,28}$ (Table 2).

Spectroscopic analysis of 3, particularly NMR data indicated that the steroidal skeleton was unaffected but both the $\mathrm{C}_{20}$ ketone and 18-methyl signals were missing. The presence of three deshielded olefinic protons at $\delta 7.34(\mathrm{~d}, \mathrm{~J}=9 \mathrm{~Hz}, \mathrm{IH}), 6.30(\mathrm{~d}, \mathrm{~J}=9 \mathrm{~Hz}, 1 \mathrm{H})$ and $6.09(\mathrm{~s}, 1 \mathrm{H})$ confirmed that the dienone system was intact, and on the basis of chemical shifts and spin-spin coupling constants these signals were assigned to the $\mathrm{C}-2, \mathrm{C}-1$ and $\mathrm{C}-4$ protons respectively. Moreover, signals due to the rings $\mathrm{B}, \mathrm{C}$ and $\mathrm{D}$ were also unaffected. These data along with the appearance of a new methylene carbon and the IR absorption bands at $3410(\mathrm{OH}), 1680(\alpha, \beta-$ unsaturated $\mathrm{C}=\mathrm{O}), 1630,1615(\mathrm{C}=\mathrm{C}) \mathrm{cm}^{-1}$, supported the assigned structure.

Table 2. Circular dichroism spectra of 2 and other related lumiproducts

\begin{tabular}{|l|c|c|c|c|c|c|}
\hline Compd. & $\lambda_{\max }(\Delta \varepsilon)$ & $\lambda_{\max }(\Delta \varepsilon)$ & Crossover $\lambda$ & $\lambda_{\max }(\Delta \varepsilon)$ & Crossover $\lambda$ & $\lambda_{\max }(\Delta \varepsilon)$ \\
\hline $\mathbf{2}$ & & $345(-4.08)$ & 315 & $280(+12.22)$ & 253 & $225(-11.70)$ \\
\hline $\begin{array}{l}\text { Related } \\
\text { lumiproducts }\end{array}$ & $355(-3.71)$ & $344.5(-3.77)$ & 311 & $275(+10.3)$ & 252 & $\begin{array}{c}\text { Short } \\
\text { wavelength } \\
-v e \text { CD }\end{array}$ \\
\hline
\end{tabular}

${ }^{\mathrm{a}}$ see refs. $[27,28]$

The NMR spectra of $\mathbf{4}$ suggested that the structural features in the rings $\mathrm{A}, \mathrm{B}$ and $\mathrm{C}$ were again conserved, while one of the side chains at $\mathrm{C}_{17}$ had been lost. In addition a strongly deshielded signal at $\delta 8.7$ (brs, exch., $1 \mathrm{H}$ ) in the ${ }^{1} \mathrm{H}-\mathrm{NMR}$ and a new signal at $\delta 124.8$ (C-17) in ${ }^{13} \mathrm{C}-\mathrm{NMR}$ suggested the presence of a hydroperoxy group in 4 . The spectroscopic indications (in the experimental section) allowed assignment of the hydroperoxide structure to 4 .

\section{Experimental Section}

General Procedures. Pure clobetasol was obtained from ZYG Pharma Pvt. Ltd., (India). The solvents used in the photoreactions were of spectroscopic grade. Irradiations at $254 \mathrm{~nm}$ were 
carried out in an immersion well type photoreactor (quartz) equipped with $20 \mathrm{~W}$ low-pressure mercury arc lamp. For irradiations at $310 \mathrm{~nm}$ the solutions were irradiated with $15 \mathrm{~W}$ phosphor coated lamps. IR spectra were recorded in $\mathrm{KBr}$ discs on a Perkin Elmer model spectrum RX1. ${ }^{1} \mathrm{H}$ NMR and ${ }^{13} \mathrm{C}$ NMR spectra were recorded on a Bruker DRX-300 spectrometer using $\mathrm{SiMe}_{4}$ as internal standard and $\mathrm{CDCl}_{3}$ as solvent. Circular dichroism spectra were measured on a Jasco-J 41A spectropolarimeter. High-resolution mass spectra were determined with a VG-ZAB-BEQ9 spectrometer at $70 \mathrm{eV}$ ionization voltages. Merck silica gel $60 \mathrm{~F}_{254}$ plates were used for analytical TLC; column chromatography was performed on Merck silica gel 60 (70-230 mesh).

Photoirradiation procedure. A solution of clobetasol (in acetonitrile or 2-propanol) was stirred and flushed with argon or oxygen (as desired) for $1 \mathrm{~h}$ before irradiation and was kept bubbling during the irradiations. The course of reaction was monitored by thin layer chromatography on pre-coated silica gel TLC plates using chloroform- acetone (9:1) mixture. After the completion of reaction (when desired conversions have reached) the solvent was removed in a rotary evaporator and products were purified by silica gel column chromatography.

Irradiation of clobetasol in argon- saturated acetonitrile. A solution of $\mathbf{1}$ ( $234 \mathrm{mg}, 0.5 \mathrm{mmol})$ in argon-saturated acetonitrile $(400 \mathrm{ml})$ was irradiated for $2.5 \mathrm{~h}$ at $254 \mathrm{~nm}$. After following the steps described in the photoirradiation procedure, $2(110 \mathrm{mg})$ was obtained as the product.

21-Chloro-9-fluoro-11-hydroxy-16-methyl-17(1-oxopropoxy)-1, 5-cyclopregn-3-ene-2, 20dione (2). Yield: $110 \mathrm{mg}$ (47\%); UV $\lambda_{\max }(\mathrm{MeOH}) 251 \mathrm{~nm}$; IR (KBr) 3400, $1675(\mathrm{C}=\mathrm{O}), 1570$ $(\mathrm{C}=\mathrm{C}), 1350,1161,1030 \mathrm{~cm}^{-1}$ (cyclopropyl); ${ }^{1} \mathrm{H}-\mathrm{NMR}\left(\mathrm{DMSO}_{6}\right) \delta 6.66(\mathrm{~d}, 1 \mathrm{H}, \mathrm{J}=6.2 \mathrm{~Hz}, \mathrm{H}-$ 4), 5.68 (d, 1H, J=6.2 Hz, H-3), 4.42 (s, 2H, H-21), 4.32 (brs, exch., OH), 2.53 (m, 1H, H-16), 3.43 (dd, 1H, J=11,5 Hz, H-11), 2.29 (m, 2H, H-23), 1.74 (m, 1H, H-8), 1.5-1.7 (m, 6H), 1.42 (dd, 1H, J=11, 2 Hz, H-14), $1.32(\mathrm{~m}, 2 \mathrm{H}, \mathrm{H}-15), 1.21\left(6 \mathrm{H}, 2 \times \mathrm{CH}_{3}\right), 1.11\left(6 \mathrm{H}, 2 \times \mathrm{CH}_{3}\right) 1.06(\mathrm{~s}$, 1H, H-1); ${ }^{13} \mathrm{C}-\mathrm{NMR}\left(\mathrm{DMSO}_{6}\right) \delta 201.3$ (C-20), 192.5 (C-2), 174.4 (C-22), 159.7 (C-4), 130.8 (C-3), 114.1 (C-9), 93.9 (C-17), 71.1 (C-11), 41.3 (C-21), 40.4 (C-1), 39.3 (C-14), 38.1 (C-8), 37.4 (C-6), 37.0 (C-13), 32.9 (C-12), 31.8 (C-15), 31.2 (C-16), 27.8 (C-23), 27.1 (C-10), 25.2 (C5), 18.7 (C-7), 14.6 (C-18) 9.4 (C-19); HRMS calcd. for $\left(\mathrm{M}^{+}\right) \mathrm{C}_{25} \mathrm{H}_{32} \mathrm{O}_{5} \mathrm{ClF}$ 466.9771, found 466.9780 .

A solution of $1(234 \mathrm{mg}, 0.5 \mathrm{mM})$ in argon-saturated acetonitrile $(400 \mathrm{ml})$ was irradiated for $2 \mathrm{~h}$ at $310 \mathrm{~nm}$. After following the steps described in general photoirradiation procedure, 3 (90 $\mathrm{mg}$ ) was obtained as main product with a trace amount of 2 , as detected on TLC.

21-Chloro-9-fluoro-11-hydroxy-16-methyl-17(1-oxopropoxy)-18,20-cyclopregn-1,4-diene-3one (3). Yield: $90 \mathrm{mg}$ (39\%); UV $\lambda_{\max }(\mathrm{MeOH}) 240 \mathrm{~nm}$; IR (KBr) 3410,1680, 1630, 1615; ${ }^{1} \mathrm{H}-$ NMR (DMSO-d 6 ) $\delta 7.34$ (d, J=9 Hz, 1H, H-2), 6.28 (d, J=9 Hz, 1H, H-1), 6.09 (s, 1H, H-4), 3.77 (s, 2H, H-21), 3.51 (brs, exch., OH), 3.34 (m, 1H, H-11), 2.37 (m, 1H, H-16), 2.21 (m, 2H, H22), 2.11 (s, 2H, H-18), 2.09 (d, 2H, H-6), 1.74 (m, 1H, H-8), 1.59 (m, 2H, H-15), 1.52 (m, 2H, $\mathrm{H}-7), 1.36\left(3 \mathrm{H}, \mathrm{CH}_{3}\right), 1.14\left(3 \mathrm{H}, \mathrm{CH}_{3}\right), 1.06\left(3 \mathrm{H}, \mathrm{CH}_{3}\right) ;{ }^{13} \mathrm{C}-\mathrm{NMR}\left(\mathrm{DMSO}-\mathrm{d}_{6}\right) \delta 185.8(\mathrm{C}-3)$, 173.4 (COOR), 167.2 (C-5), 154.7 (C-1), 129.2 (C-2), 125.4 (C-4), 102.2 (C-17), 99.8 (C-9), 98.1 (C-20), 72.2 (C-11), 55.3 (C-10), 46.9 (C-21), 42.1 (C-14), 39.4 (C-8), 37.0 (C-13), 35.2 (C- 
12), 34.9 (C-18), 33.6 (C-6), $28.7(\mathrm{C}-16), 25.8(\mathrm{C}-7), 19.2\left(\mathrm{CH}_{3}\right), 17.4\left(\mathrm{CH}_{3}\right), 16.1\left(\mathrm{CH}_{3}\right)$; HRMS calcd. for $\left(\mathrm{M}^{+}\right) \mathrm{C}_{25} \mathrm{H}_{32} \mathrm{O}_{5} \mathrm{ClF} 466.9771$, found 466.9765 .

Irradiation of clobetasol in oxygen saturated acetonitrile. A solution of $1(234 \mathrm{mg}, 0.5 \mathrm{mM})$ in oxygen-saturated acetonitrile $(400 \mathrm{ml})$ was irradiated for $2.5 \mathrm{~h}$ at $254 \mathrm{~nm}$ and $310 \mathrm{~nm}$. After following the steps described in the general photoirradiation procedure, compound $2(112 \mathrm{mg}$, $48 \%$ ) was obtained as the product at $254 \mathrm{~nm}$; whereas a complex mixture of the products was obtained at $310 \mathrm{~nm}$.

Irradiation of clobetasol in argon-saturated 2-propanol. A solution of $1(234 \mathrm{mg}, 0.5 \mathrm{mM})$ in argon-saturated 2-propanol $(400 \mathrm{ml})$ was irradiated for $2 \mathrm{~h}$ at $254 \mathrm{~nm}$ and at $310 \mathrm{~nm}$. After following the steps described in the general photoirradiation procedure, compound $2(120 \mathrm{mg}$, $52 \%$ ) was obtained as the product at $254 \mathrm{~nm}$. Whereas at $310 \mathrm{~nm}$ both the compounds $2(35 \mathrm{mg}$, $15 \%)$ and $3(86 \mathrm{mg}, 37 \%)$ were obtained as the products.

Irradiation of clobetasol in oxygen-saturated 2-propanol. A solution of 1 ( $234 \mathrm{mg}, 0.5 \mathrm{mM})$ in oxygen-saturated 2-propanol $(400 \mathrm{ml})$ was irradiated for $2.5 \mathrm{~h}$ at $254 \mathrm{~nm}$ and $310 \mathrm{~nm}$. After following the steps described in the general photoirradiation procedure, compound 2 (130 $\mathrm{mg}$, $56 \%$ ) was obtained as the product at $254 \mathrm{~nm}$. At $310 \mathrm{~nm} 2$ (42 mg, 18\%) and 4 (100 mg, 43\%) were obtained as the products.

9-Fluoro-17-hydroperoxy-16-methyl-17(1-oxopropoxy) androsta-1,4-diene-3-one (4). Yield: $100 \mathrm{mg}$ (43\%); UV $\lambda_{\max }(\mathrm{MeOH}) 241 \mathrm{~nm}$ IR (KBr) 3410, 1660, 1615, 1610; ${ }^{1} \mathrm{H}-\mathrm{NMR}$ (DMSOd d $\delta 8.7$ (brs, exch., OOH), 7.14 (d, 1H, J=9 Hz, H-2), 6.30 (d, J=9 Hz, 1H, H-1), 6.09 (s, 1H, H4), 3.43 (m, 1H, H-11), 2.29 ( (m, $\left.2 \mathrm{H},-\mathrm{OOCCH}_{2} \mathrm{CH}_{3}\right), 2.35$ (m, 1H, H-16), 2.1 (brs, exch., OH), 1.5-1.7 (m, 5H, H-8, H-12, H-15), 1.36 (s, 3H, H-19), 1.16 (s, 3H, H-18), 2.0 (m, 2H, H-6), 1.52 (m, 2H, H-7), 1.40 (s, 1H, H-14), $1.11\left(3 \mathrm{H}, \mathrm{CH}_{3}\right), 1.02\left(3 \mathrm{H}, \mathrm{CH}_{3}\right) ;{ }^{13} \mathrm{C}-\mathrm{NMR} 185.8$ (C-3), 173.1(-OCOCH${ }_{2} \mathrm{CH}_{3}$ ), 168.3 (C-5), 155.4 (C-1), 128.4 (C-2), 124.2 (C-4), 100.3(C-9), 70.8 (C11), 54.7 (C-10), 43.6 (C-16), 39.1 (C-8), 37.6 (C-14), 33.0 (C-6), 33.7 (C-13), 30.3 (C-12), 29.6 (C-15), $28.2\left(-\mathrm{OCOCH}_{2} \mathrm{CH}_{3}\right), 25.2$ (C-7), 24.8 (C-17), 18.9 (C-19), 11.3 (C-18), 9.4 ($\left.\mathrm{OCOCH}_{2} \mathrm{CH}_{3}\right)$; HRMS calcd. for $\left(\mathrm{M}^{+}\right) \mathrm{C}_{23} \mathrm{H}_{31} \mathrm{O}_{6} \mathrm{~F} 422.6939$, found 422.6930 .

\section{References}

1. Karoon, J.; Oliver, A. M.; Paddon-Row, M. N.; Verhoven, J. W. J. Am. Chem. Soc., 1990, 112, 4868.

2. Closs, G. L.; Johnson, M. D.; Miller, J. R.; Piotrowiak, P. J. Am. Chem. Soc., 1989, 111, 3751.

3. Morrison, H. Rev. Chem. Intermed. 1987, 8, 125.

4. Wu, Z. Z.; Nash, J.; Morrison, H. J. Am. Chem. Soc. 1992, 114, 6640.

5. Wu, Z. Z.; Morrison, H. J. Am. Chem. Soc. 1992, 114, 4119.

6. Morrison, H.; Pallmer, M.; Loeschen, R.; Pandey, R.; Muthuramu, K.; Maxwell, B., J. Org. Chem. 1986, 51, 4676. 
7. Wu, Z. Z.; Morrison, H. Photochem. Photobiol. 1989, 50, 525.

8. Ricci, A.; Fasani, E.; Mella, M.; Albini, A. J. Org. Chem. 2001, 66, 8086.

9. Ricci, A.; Fasani, E.; Mella, M.; Albini, A. J. Org. Chem. 2003, 68, 4361.

10. Suzuki, T.; Kato, T.; Kitagaki, T.; Ono, M.; Shirakawa, K.; Nagata, M.; Konishi, R. J. Toxicol. Sci. 1996, 21, 475.

11. Keknes, A.; Jahn, P.; Lange, L. J. Am. Acad. Dermatol. 1993, 28, 786.

12. Uchiyama, H.; Tanaka, T.; Uehara, N.; Nakamura, M.; Tsuji, M.; Shinomiya, M.; Tanaka, H. J. Toxicol. Sci. 1992, 17, 283.

13. Albini, A.; Fasani, E., DRUGS: Photochemistry and Photostability, Royal Society of Chemistry: Cambridge, 1998.

14. Yang, C. A.; William, S. I. R.; MacFarlane I. A. British J. Clin. Pract. 1991, 45, 61.

15. Martindale, The Extra Pharmacopoeia, $31^{\text {st }}$ Edn, Royal Pharmaceutical Society: London, 1996; pp 1093.

16. Dollerey, C. Therapeutic Drugs, $2^{\text {nd }}$ Edn.; Churchi 11 Livingstone: London, 1999, pp 266.

17. Reisch, J.; Enkel, G.; Ekiz-Guecer, N.; Nolte, G. Liebigs Ann. Chem. 1992, 63.

18. Reisch, J.; Topaloglu, Y.; Henkel, G. Acta Pharm. Tech. 1986, 32, 115.

19. Ogata, M.; Noro, Y.; Yamada, M.; Tahara, T.; Nishimma, T. J.Pharm. Sci. 1998, 87, 91.

20. Suzuki, T.; Kato, T.; Kitagaki, T.; Ono, M.; Shirakawa, K.; Nagata, M.; Konishi, R. J. Toxicol. Sci. 1962, 2, 475.

21. Takacs, M.; Ekiz-Guecer, N.; Reisch, J.; Gergely-zobin, A. Pharm. Acta Helv. 1991, 66, 137.

22. Ekiz-Guecer, N.; Reisch, J.; Nolte, G. J. Pharm. Biopharm. 1991, 37, 234.

23. Thoma, K.; Kerker, R.; Weissbach, C. Pharm. Ind. 1987, 49, 961.

24. Williams, J. R.; Moore, R. H.; Li, R.; Weeks, C. M. J. Org. Chem. 1980, 45, 2324.

25. Schaffner, K.; Demuth, M. In Rearrangements in Ground State and Excited State De Mayo, P., Ed.; Academic Press: New York, 1980; Vol. 3, pp 281.

26. Caine, D. In CRC Handbook of Organic Photochemistry and Photobiology, Horspool, W. M.; Song, P. S. Eds.; CRC Press: Boca Raton, 1995, pp 701.

27. Feri, J.; Ganter, C.; Kagi, D.; Kocsis, K.; Miljkovic, M.; Siewinski, A.; Wenger, R.; Schaffner, K.; Jeger, O. Helv. Chim. Acta 1966, 49, 1049.

28. Schaffner, K.; Snatzke, G. Helv. Chim. Acta 1965, 48, 347. 